Article

\title{
Eroding Land and Erasing Place: A Qualitative Study of Place Attachment, Risk Perception, and Coastal Land Loss in Southern Louisiana
}

\author{
Catherine E. Lambert ${ }^{1, *} \mathbb{\infty}$, Jason R. Holley ${ }^{1}\left(\mathbb{D}\right.$, Katherine A. McComas ${ }^{1}$, Natalie P. Snider ${ }^{2,3}$ and Grace K. Tucker ${ }^{2}$ \\ 1 Department of Communication, College of Agriculture and Life Sciences, Cornell University, \\ Ithaca, NY 14853, USA; jrh374@cornell.edu (J.R.H.); kam19@cornell.edu (K.A.M.) \\ 2 Environmental Defense Fund, Washington, DC 20009, USA; nsnider@edf.org (N.P.S.); \\ gtucker@edf.org (G.K.T.) \\ 3 Center for Environmental Science, University of Maryland, College Park, MD 20742, USA \\ * Correspondence: cel247@cornell.edu
}

Citation: Lambert, C.E.; Holley, J.R.; McComas, K.A.; Snider, N.P.; Tucker, G.K. Eroding Land and Erasing Place: A Qualitative Study of Place

Attachment, Risk Perception, and Coastal Land Loss in Southern Louisiana. Sustainability 2021, 13, 6269. https://doi.org/10.3390/ su13116269

Academic Editor: Carmen Elrick-Barr

Received: 20 April 2021

Accepted: 25 May 2021

Published: 1 June 2021

Publisher's Note: MDPI stays neutral with regard to jurisdictional claims in published maps and institutional affiliations.

Copyright: (c) 2021 by the authors. Licensee MDPI, Basel, Switzerland. This article is an open access article distributed under the terms and conditions of the Creative Commons Attribution (CC BY) license (https:/ / creativecommons.org/licenses/by/ $4.0 /)$.

\begin{abstract}
Southern Louisiana and its coastal bayous are sites of both frequent flooding and rapid coastal land loss, exacerbated by the increasing effects of climate change. Though much work has examined flood risk perceptions in coastal areas, few studies have considered the qualitative and contextual dimensions of perceptions of coastal land loss and its associated impacts, and how these perceptions relate to local culture, place, and intentions to mitigate personal exposure to risk. We conducted six focus groups in areas with distinct exposure to coastal land loss. Participants expressed strong attachment to community, culture, and place. Personal ties to land loss through family or social connections, experiences with fishing and water-based activities, and indirect impacts on Louisiana's seafood industry and cuisine provided a lens for understanding the immediate impacts of coastal land loss. Participants felt that exposure to the risks of land loss was inevitable and that mitigation was beyond individual efforts, a feeling that manifested both as pessimism and as a resilient focus on collective action. Considering state history with political corruption, participants generally distrusted state-level mitigation initiatives. These findings shed light on the qualitative dimensions of coastal land loss perceptions in southern Louisiana and their relation to place attachment, mitigation intentions, and sources of risk information. While participants with personal ties to risk report feelings of exposure and inevitability, they are also embedded in communities with strong ties to place. This nuance only complicates the meanings that individuals associate with land loss and the actions that they are motivated to take; impacts of coastal land loss on the landscape and distinct place characteristics of southern Louisiana may lead to significant disruption to identity and well-being, but also provide a pathway for risk awareness and potential motivation of collective mitigation actions.
\end{abstract}

Keywords: coastal land loss; risk perception; place attachment; risk mitigation; community

\section{Introduction}

Southern Louisiana, home to nearly half of the state's population, faces increasing precarity due to climate change-driven flood risks and land loss along the coast [1]. Over the last 80 years, at least 2000 square miles of land area has disappeared, from the combined effects of subsidence, sea level rise, major hurricane events, and oil and gas infrastructure, among other stressors [2]. The flood control structures that regulate the Mississippi River have limited the deposition of sediments and nutrients needed to maintain broader coastal ecosystems, while other human activity such as the construction of canals for oil and gas production has also exacerbated wetland degradation and land loss [1,2]. Accelerated sea level rise is projected to lead to the irreversible collapse of the Mississippi Delta's coastal marshes over the next century [3], and this loss of wetlands that serve as protection against storm surges further exacerbates flood risks [1]. 
Though precarious, Louisiana's coastal waterways are rich in natural, cultural, and economic resources, supporting significant economic activities in commercial fisheries, oil and gas drilling, shipping, and tourism [1]. The historical and cultural heritage of the region, from the cuisine of Cajun Country to the festivals and krewes (a social organization associated with planning Mardi Gras events) of New Orleans, is renowned, and communities in the coastal region include Native Americans, Cajuns, Creoles, more recent immigrant groups such as Vietnamese, Croatians, and Haitians, and a diverse mix of others with deep roots to the coastline and its waterways and natural resources [4]. In the face of climate impacts that pose a threat not only to the physical landscape and ecosystems but also to Louisiana residents' livelihoods, identities, and heritage, it is crucial to understand how residents perceive these threats and what actions that they may be willing to take to mitigate their exposure to risk and adapt to ongoing impacts. Though state and federal projects aim to mitigate land loss and flooding, personal actions by residents may also be required to prevent or limit damage and losses.

The aim of this study is to examine the qualitative and contextual dimensions of individuals' perceptions of risks from coastal land loss and flooding, mitigation actions, and the importance of place, culture, and context, as well as the information sources that individuals use to gain knowledge about coastal land loss and flood risks. We conducted six focus groups in southeastern and central Louisiana in the fall of 2019. Below, we review the literature on risk perception, coastal land loss, and place attachment in Louisiana before discussing the methods and results of this study.

\section{Literature Review}

\subsection{Coastal Land Loss, Flood Risk Perception, and Behavior}

Risk reduction in the face of climate change impacts requires both mitigation and adaptation approaches, reducing emissions while also reducing the negative effects of climate change on coastal regions through a wide range of strategies [5,6]. A general consensus in climate change adaptation literature acknowledges the need to focus on community-based approaches, the role of local knowledge and participation, and the social dimensions of barriers to adaptation [7-10]. For coastal communities, research on adaptation to sea level rise has identified unique vulnerabilities of fisheries and rural coastal communities, as well as the role of cultural and historical landscapes [11-13].

Coastal land loss involves the intertwined forces of sea level rise, subsidence, human activities such as oil and gas development, and other stressors, with local impacts visible in a variety of ways both long term and immediate, as during acute flooding events and storms. Climate change adaptation literature on the effects of sea level rise, diffuse climate impacts, and community perspectives can be linked with a significant body of work in risk communication, which has investigated flood risk perception more broadly. Understanding how people perceive and understand flood risk and how these perceptions shape their actions is vital for effectively managing risk and designing communication strategies for risk mitigation. Individuals' perceptions of risk are built upon their experiences, beliefs, and values, along with social, cultural, and psychological factors [14,15]. Personal experience and trust in authorities have been shown to strongly influence risk perception of natural hazards, while factors such as demographics, media coverage, and indirect experiences also play a role [16]. In the context of flooding and coastal land loss, investigations of risk perception have also highlighted personal experience of floods and evacuation orders [17,18]. In New Orleans itself, Gotham et al. [18] found that residents of neighborhoods that had flooded during Katrina had higher levels of risk perception. In turn, some studies have suggested that personal experiences with severe weather events like flooding and storms influence attitudes towards climate change and climate change mitigation and adaptation efforts [19-21].

Risk coping behaviors vary widely in difficulty and accessibility, ranging from relocation, voting and community engagement to household infrastructure modifications aiming to limit property damage, loss of land, and personal exposure to risk. Risk perception 
alone does not necessarily motivate taking action to mitigate or cope with risk; drivers of protective behaviors also include beliefs about the behaviors, the stakeholders involved, and additional factors like experience, knowledge, and socioeconomic factors [16,22]. Key antecedents of behavior identified by protection motivation theory [23], for instance, include both the appraisal of the risk and appraisals of the coping behavior, involving the perceived self-efficacy, effectiveness (or response efficacy), and costs of the behavior [22]. Flood-coping appraisals have been shown to contribute to adoption of a variety of flood mitigation behavior, including insurance purchases, adapted building use, and structural measures [24,25]. Also relevant are appraisals of the stakeholders involved; perceived stakeholder characteristics that correlate with behavioral intentions include trust, expertise, and perceived responsibility for managing risk, as Lindell and Perry [26] describe in the protective action decision model. Personal experience with hazards like floods $[27,28]$ and hurricanes [29] has also been shown to relate positively to risk mitigation behaviors and intentions.

\subsection{Place Attachment and Coastal Landscapes}

Research in community-based climate adaptation has highlighted a need for contextspecific approaches $[6,13,30,31]$ that take into account place-based characteristics; meanwhile, the usefulness of concepts derived from place theory for perceptions of environmental risks has also received increasing attention in recent literature. For risks like coastal land loss that involve drastic changes to the landscape, the concept of place attachment may be a particularly important factor shaping perceptions and behavior. Place attachment consists of the emotional bond between individuals or groups and their environment, rooted in experiences, knowledge, beliefs, and behaviors within a setting [32], and the meanings attributed to place [33]. Memory also serves as an anchor for place attachment, lending a sense of continuity with environments of the past which can be critical to emotional well-being [34]; when place attachment is disrupted, a loss of identity and of stability can ensue [35].

Research on the precise relationship between place and risk has suggested conflicting results. Reviewing research on the relationships between place attachment, risk perception, and coping behaviors, Bonaiuto et al. [36] found both positive and negative associations between attachment and risk perception, and between attachment and coping behaviors. In some cases, increased attachment was associated with diminished risk perceptions [37-43] and negatively correlated with intentions to mitigate risk $[38,43,44]$, particularly mitigation in the form of relocation and evacuation [40,41,45-51]. In other studies, place attachment is positively associated with risk perception [47,52], and a stronger sense of place is associated with heightened levels of concern $[53,54]$. Positive relationships between place attachment and behavior were seen for such cases as willingness to clean up beaches post-oil spill [55], wildfire mitigation measures [56], tornado recovery actions [57], and pro-environmental behavior [52].

The most frequently observed patterns were that strongly attached individuals had higher awareness of risks, but were less likely to engage in coping behaviors, particularly difficult behaviors like relocation [36]. In the context of flood risks, some evidence has shown that attachment to place is associated with increased flood preparedness [58]. In a study of a flood-impacted Australian town, Boon [46] found that strong sense of place promoted disaster resilience while negatively impacting desire to relocate. Further reflecting the heterogenous effects of place attachment, Haney [17] found that, in the aftermath of a flood, attachment led to increased worry about future flooding but also increased the odds of planning to stay in place; experiencing a flood had "reinvigorated their place attachment and strengthened their resolve to rebuild" (p. 9).

The symbolic meanings attributed to place also play a role; when important place meanings are threatened, people are more likely to fight to protect their place [33]. Coastal and riverine landscapes carry their own unique meanings and senses of place for those who live, work, and visit around them, which have been shown to influence flood risk 
perceptions; positive identification with waterbodies has been associated with reduced risk perception, and different meanings relate to different preferences for flood management strategies [59]. The activities and behaviors enabled by waterscapes also contribute to how residents relate to risk. Participation in outdoor recreational activities in the Everglades, for example, influenced perceptions of climate change risks and preferences for sea level rise mitigation strategies [60].

Fishing activity, both commercial and recreational, provides a strong contribution to place attachment and identity, potentially influencing attitudes and actions towards threats to fishing resources $[61,62]$. Fisheries landscapes generate a place identity rooted in fishing as a livelihood and a way of life [63,64], as a material culture [65], and as an element of place memory, both through memories of the activity itself and of past traditional fishing places [63]. Place elements in fisheries communities have also been shown to be important aspects of the connections and feedbacks that can drive community adaptation and resilience [13]. With the second-highest volume of commercial fish landings of any state in the US [66], Louisiana's prominent fishing industry and infrastructure may also be major components of sense of place and attachment in the coastal region.

For regions like coastal Louisiana with rich sociocultural and historical meanings, the attachments and meanings that individuals ascribe to place may be of particular importance in effecting how they perceive and respond to risk. Burley et al. [67] identifies a positive association between place attachment and awareness of hurricane risk and coastal land loss in Louisiana, noting that coastal communities were strongly attached to their area and conceptualized it in terms of fragility and uniqueness. Chamlee-Wright and Storr [68], examining sense of place in New Orleans post-Katrina, found that place attachment was highest among those who chose to return rather than relocate, motivated by their sense of the cultural uniqueness of the city. In a more recent study on climate risk management in New Orleans, Bessette et al. [69] noted that participants' understanding of risk and management strategies was framed through three fundamental values: fostering jobs and a healthy economy, protecting ecosystems and biodiversity, and finally, preserving New Orleans" "unique culture, traditions, and historically significant neighborhoods" (p. 1993). Existing research indicates an important role of place and context in shaping risk perceptions and behaviors in coastal Louisiana, alongside factors like trust and direct and indirect experience. Drawing on these areas of literature, we investigate the contextual and qualitative dimensions of coastal land loss risk perceptions and risk mitigation behaviors, exploring the following research questions:

RQ1: What factors influence residents' perception of the risks and impacts of coastal land loss in Louisiana?

RQ2: What factors are central in influencing residents' attitudes towards mitigation behaviors?

RQ3: What is the role of place, culture, and experience in influencing risk perception and mitigation behaviors?

\section{Materials and Methods}

We used qualitative, semi-structured focus group methods to capture richer insight into these contextual dimensions, allowing for a situated understanding of participants' experiences and attitudes. We selected coastal Louisiana as our study site for two primary reasons: (1) Louisiana is a location of rapid coastal land loss and (2) prior research indicates the presence of prominent place attachments, meanings, and cultural dimensions that may significantly shape attitudes towards coastal land loss and associated risks and behaviors, enabling a rich exploration of the concepts of interest.

We held six focus groups in the period October-November of 2019 in locations in Louisiana with distinct exposure to flood risks and coastal land loss, both inside and outside the levee system protecting communities from flooding. The focus groups took place in (1) Alexandria; (2) North Shore; (3) north Jefferson Parish; (4) the 9th Ward; (5) Plaquemines Parish; and (6) Jean Lafitte (Figure 1). The city of Alexandria (1) is a 
small city of approximately 48,000 located in the center of the state along the Red River, 100 miles northwest of Baton Rouge. The North Shore (2) refers to the northern side of Lake Pontchartrain, including the communities of Covington, Mandeville, and Slidell. The north Jefferson Parish (3) session took place in Jefferson, part of the New Orleans metropolitan area located to the west of New Orleans on the north side of the river. The 9th Ward (4) is a neighborhood of New Orleans on the eastern edge of the city, bordered by the Mississippi River on its southern edge and Lake Pontchartrain on its north. Plaquemines Parish (5) extends along both banks of the Mississippi from the southern edge of New Orleans to the end of the river delta at Port Eads; it is the epicenter of much of Louisiana's land loss. Participants attending the Plaquemines Parish discussion were members of the Atakapas-Ishak/Chawaska Tribe from Grand Bayou Village, also indicated in Figure 1. Jean Lafitte (6) is located on Bayou Barataria in south Jefferson Parish. We distinguish the six sites based on their location in relation to the mainstem Mississippi River levee system: the comparatively inland sites of Alexandria (1) and the North Shore (2), the north Jefferson Parish (3) and 9th Ward (4) sites within the levee system, and the Plaquemines Parish (5) and Jean Lafitte (6) sites located south of New Orleans and outside of the levee system.

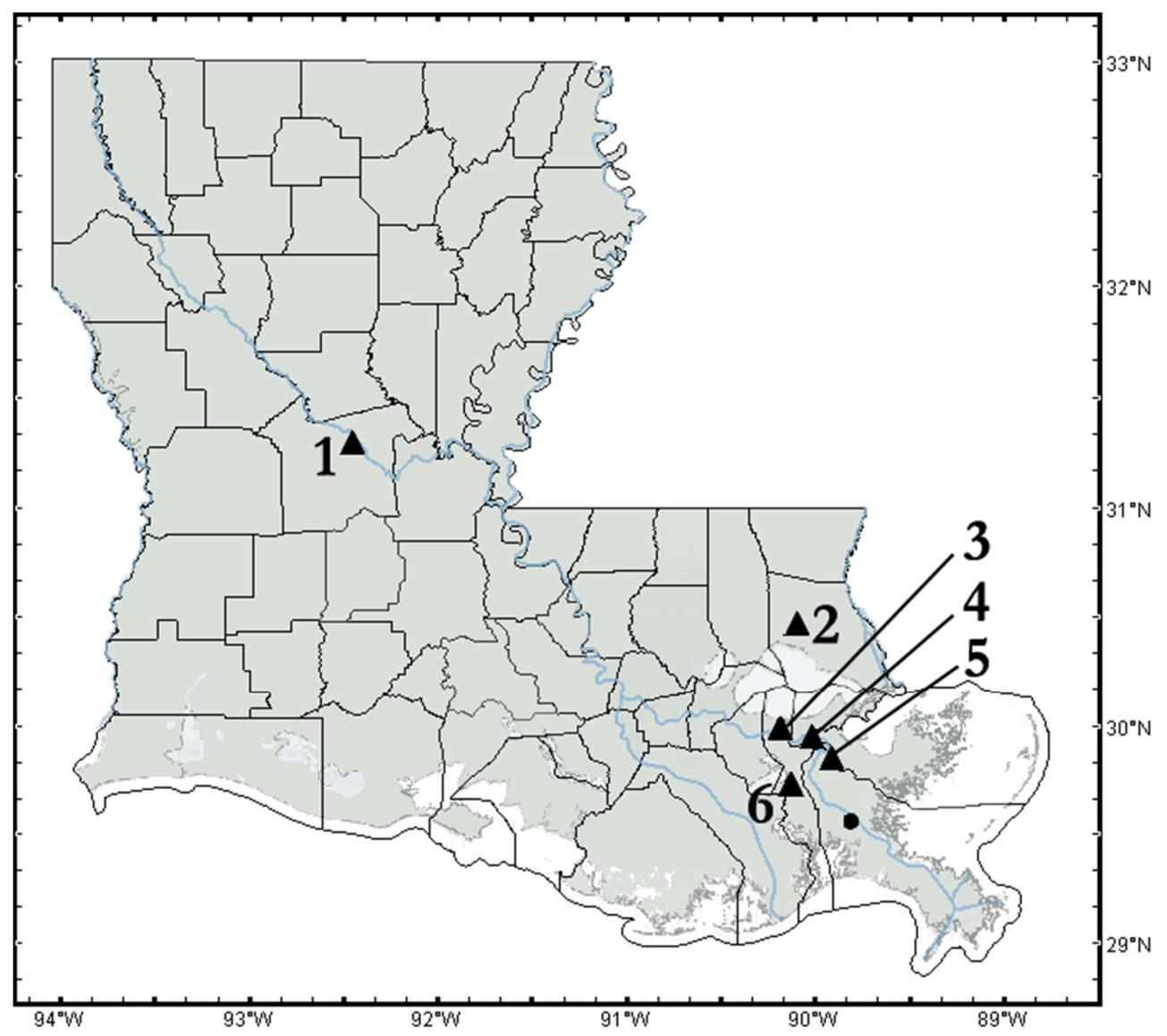

Figure 1. Location of the six focus groups within Louisiana, indicated by triangles: 1. Alexandria 2. North Shore 3. North Jefferson Parish 4. the Ninth Ward 5. Plaquemines Parish and 6. Jean Lafitte. Circle to the southeast of site 6 indicates the location of Grand Bayou Village.

We obtained ethical approval from the Institutional Review Board of Cornell University. We recruited participants through geotargeted Facebook ads aimed at residents of the target areas by zip code; we supplemented Facebook ads with flyers in community spaces. We engaged a total of 45 participants in the focus groups, ranging from 4 to 12 at each session. We screened participants to ensure geographic distribution in the targeted communities and that there were not multiple participants from the same household. Written 
informed consent for participation and audio-recording was obtained from all participants at the beginning of each session.

The sessions lasted for approximately $1.5-2 \mathrm{~h}$ and took place in community spaces such as public library meeting rooms and community halls. The sessions followed a semistructured format with discussion questions that began with a focus on participants' sense of place and community before raising questions of land loss risks, mitigation behaviors, and the information sources participants used to access related information. We also asked participants whether they saw land loss risks and mitigation as related to climate change and climate change mitigation. We recorded and later transcribed the sessions, and each session included a moderator and two note-takers from the research team.

Data analysis consisted of thematic coding of session transcripts using the coding software program Atlas.ti version 8.4.24 [70], along with field notes taken during the focus groups. We coded the transcripts and notes into the major categories discussed below. Following Charmaz [71], we coded using a qualitative, inductive approach allowing central themes to emerge from the data through close reading, with key concepts from the literature reviewed above acting as sensitizing concepts. Coding indicated that the number of sessions was adequate to reach theoretical saturation, as further analysis did not reveal additional categories and themes.

\section{Findings}

\subsection{Place: "No Other Place on the Planet Like It"}

Across the focus groups, participants generally expressed high levels of attachment to place, either to Louisiana as a whole or to their individual communities. Participants spoke broadly of food, music, culture, and community as their favorite aspects of Louisiana, often noting the uniqueness of the state and the city of New Orleans with a sense of pride: there's "no other place on the planet like it". The sense of community that participants described cited the friendliness and hospitality of their neighbors and communities and a vibrant culture of community events like crawfish boils, barbecues, and second-line parades (a New Orleans tradition in which the "main line" of a parade, consisting of a brass band, a krewe, or a wedding or funeral party, is followed by a growing "second line" of spectators who join the procession and take part in the music and dancing). In contrast to the perceived coldness and rapid pace of more northerly states and major cities, participants characterized Louisiana as a more laid-back place, where passersby take the time to exchange greetings on the sidewalk and the people "really know how to have a good time and enjoy life". These characterizations of Louisiana and high levels of attachment were consistent across all focus group locations.

The ability to pursue activities around water, fishing, and hunting were also linked to an attachment to the state. Participants discussed Louisiana's seafood-rich cuisine as a key characteristic of the state, and for some, the importance of food to Louisiana culture went beyond the cuisine itself and included a sense of connection with nature and the environment. As one participant put it, referring to New Orleans, "The city has not lost touch with nature ... We know where food comes from. We know that food comes from the animals and plants, which people in other cities seem kind of dubious about". Many participants also described a strong attachment to place drawing on family ties, both current ("I've been a lot of places, but this is where all my family is") and based on deep-rooted histories with the land and the livelihoods that their families pursued. One participant described their family's preference for being on the water, so that "we can go to the beach, go fishing, go hunting, harvest wild stuff. My family has been in this area from up and down Mississippi since like the 1780s". In the Plaquemines Parish session, the participants, members of a Native American community on the frontlines of coastal impacts, expressed a deep attachment to their homeland: "Home is more than just the house you live in, or the geographic space you occupy. It's your spiritual, your metaphysical, your mental space. Everything that connects you to a certain place that goes beyond just the tangibles ... It helps with your mental health, your wellbeing, the essence of who you are". 
Despite the strong attachment to place, participants also noted changes in their communities over time. They called out erosion as having altered the physical landscape, while perceived declines in Louisiana's fisheries lead to one participant referring to those who fished for their livelihoods as a "dying breed". Beyond physical land losses, changes also included a loss of connectedness and a subsequent increase in the difficulty of getting things done in the neighborhood or town: "back in the day, you knew those guys, you could go and talk to them or you knew somebody that knew them who could go in and talk to them" to address community issues. Others viewed change as an inevitable part of life in southern Louisiana; for the Native American participants in the Plaquemines Parish session, acceptance of impermanence and adaptation to the processes of change in nature were part of both their history and continued maintenance of identity in the region.

\subsection{Experience as Knowledge: "It's about Living It"}

When asked whether coastal land loss was a common topic of conversation, participants generally noted that it only came up when something had happened to draw public attention, like a storm, or if there was a personal connection or impact in their social network. Participants cited a wide range of news sources as places they would trust to look for information, including local news, the Louisiana Department of Fish and Wildlife, and Google, but the primary way they learned about land loss was from family, friends, and personal experience. Participants were generally unfamiliar with specific quantifiable impacts of land loss beyond a popular but outdated statistic relating the rate of land loss to the size of a football field. However, participants had a general awareness of coastal erosion as a significant issue facing the state.

Familiarity with and knowledge about coastal land loss was most often related to either indirect experiences through social connections or direct, personal experience. Participants cited conversations with friends or family living closer to the coast who have been impacted by Gulf waters encroaching on their homes or local roads being washed out: "You pick it up anecdotally, my friends are like 'Well, you know Hackberry, god rest its soul.' 'What are you talking about?' 'Well, you can't get there anymore.'” Many participants also noted learning from older residents who recalled the changes to the landscape, "hearing their stories like, damn, that used to exist? This island used to exist [here]"?

Many of these recollections were related to activities on the water that allowed observations of the ongoing changes; during fishing trips or kayak paddles, participants recounted islands being missing and favorite fishing spots gone: "It's about living it-islands disappear, fishing disappears, families disappear because they're moving on". While participants at the inland and within-levee locations were more likely to have indirect connections with land loss, direct experience was most common at the Jean Lafitte and Plaquemines Parish discussions outside of the levee system, where participants lived and worked on the water. Residents of the Grand Bayou village at the Plaquemines Parish session discussed the immediacy of land loss in their daily lives and its impact on subsistence activities: "We talk about land loss because we're still subsisting users. We're still fishing, we still do the tracking, the hunting ... That's your food sources. So it's not like you talk about land loss, you talk about land loss and how that plays out in your life".

\subsection{Risk: "It's Bigger Than Us"}

When asked about their views on the risks of coastal land loss, there was a general awareness of negative impacts that varied from distant concerns about changes to Louisiana's distinct shape on the map to immediate concerns about livelihood and safety, though participants primarily viewed the issue in terms of flood risk. Personal concerns about direct exposure to risk included damage or loss of homes, impacts of flooding, and loss of jobs; direct personal exposure to risk was most commonly expressed in the Plaquemines Parish and Jean Lafitte sessions, the former including a community accessible only by water, and the latter including a commercial crab fisherman. Participants in the inland locations of Alexandria and the North Shore also raised concerns about indirect 
ripple effects of land loss such as displacement from coastal areas inland to their areas, with subsequent impacts to the housing market and tax bases. Concerns about the economic impacts were also common, particularly the indirect effects on seafood prices, restaurants, tourism, and recreational activities.

Participants felt that they have little to no control over coastal land loss and their exposure to risk. The progression of coastal land loss was seen as inevitable and widereaching: "sooner or later, everybody's going to be affected by land loss. And they have no way to stop it". The scale of the problem and the perceived lack of mitigation ability lead for some to a fatalistic view of the state's future, with one participant stating plainly that "The reality of it is we're going to lose Louisiana and much of the Gulf Coast, eventually". This sense of inevitable land loss was closer and more immediate for the 9th Ward, Plaquemines Parish, and Jean Lafitte groups, and more distant for the Jefferson Parish, Alexandria, and North Shore groups, but each expressed land loss as being a matter of when, not if. When asked about the timeline for addressing land loss, one Alexandria participant responded simply, "Too late".

Another theme found alongside the sense of inevitable risk for some participants was being accustomed to risk, particularly evident among the 9th Ward participants, residents of a neighborhood that experienced catastrophic flooding during Hurricane Katrina. They expressed a feeling of simply having to live with the potential risks, in part because these participants primarily associated flooding with hurricanes and the inevitable "Big One" rather than the broader issue of land loss. As one participant said, "It's still risky for us, but we don't see a lot of regular flooding, only when certain hurricanes come by. So I don't feel as threatened where I live". Hurricane-related flooding, despite the catastrophic potential, was viewed as predictable, because of the lead time of warning before a storm. Faith in the levee system was part of this attitude: "I don't see the city flooding like Katrina because that was the breaching of the levees, and now they have the gates that they close off".

The sense of inevitable risk was for some participants linked to awareness of the global risks of climate change: "where can you go that you will guarantee that you will not be negatively impacted"? For this Plaquemines Parish participant, however, this inevitability was linked to a sense of resilience: an intention to face the risks in their community, rather than trying to leave and avoid risks altogether. For some participants, recognition of the risks that they were exposed to was matched by expressions of optimism and adaptation, rather than fatalism. Attitudes towards climate change risks overall were mixed; participants included several who denied the existence of climate change. Among remaining participants, the relationship between climate change, coastal land loss, and flooding was unclear. Some raised the connections between warming water in the Gulf, increased storm strength, and increased erosion, along with effects on fisheries. Others saw the two phenomenon as entirely separate issues, despite acknowledging the realities of climate change. Connecting the two issues was seen by one participant as a hindrance in addressing land loss, as "that's where people get lost in the weeds, for me ... in terms of efforts to fix land erosion, we got to separate the two issues". Despite mixed levels of belief in climate change and its relationship to flooding risks, there was a general sense of risk increasing over time, particularly in relation to Hurricane Katrina as a tipping point, with multiple remarks along the lines of "it never used to flood like this before Katrina".

References to their children and future generations provided a framework for participants to discuss risks over longer time spans: "When our children inherit that house when we're gone, do they have something to hold on to in the future that's of value"? The loss of property and the investments that had been made into the land was only one part of the potential loss: "granted, there's insurance that'll cover some things, but it can't get back pictures and memories". Others described the risks of coastal land loss more distantly, focusing on the impacts on future generations in a way that emphasized the scope of the problem: "It absolutely is bigger than us, because we have to think about the generation that's coming after us. And what are we doing to prepare them to ensure that they'll be 
able to enjoy the Gulf Coast and all these other things, which will ultimately affect second lines, crawfish boils, and all these other wonderful things that we do in the city"?

\subsection{Action: "Nothing Is Ever Too Big"}

The sense of inevitability surrounding coastal land loss led to a general attitude of pessimism that individual direct actions could help the issue. The enormity of the issue made mitigation too large a task to translate into concrete individual actions. Participants generally described few personal behaviors to mitigate or adapt to the risks beyond scattered mentions of recycling, efforts to improve drainage on their properties, and elevating their homes, as well as a familiarity with a long-running Christmas tree recycling program that uses the trees to protect the coastline. One participant described efforts by her krewe to plant trees in the neighborhood, while another noted having added nutria (an invasive species of semi-aquatic rodent that overgraze on marsh grasses, contributing to saltwater inundation and coastal land loss [72]) to the menu at gatherings focused on cooking wild game, as a way to contribute to erosion prevention.

Instead, when asked about what could be done to protect against coastal land loss, participants predominantly focused on political actions and community engagement efforts. There was a general consensus among most participants across the six sessions that addressing the issue required action at the governmental level; a sense, again, that it was "bigger than them". Mitigation then became about collective action, with calls for grassroots efforts to counter the sense of overwhelming inevitability: "Nothing is ever too big ... we have to realize the power that we have". Some participants raised the need for education about coastal land loss in order to raise awareness; others focused on political efforts like signing petitions, attending events, protesting, and voting for new representatives who would be more active in addressing the issue. An exception to the emphasis solely on political efforts was the Plaquemines Parish session, which focused both on advocacy and on direct mitigation and adaptation efforts in the community. They described actions like elevating their homes and current discussions of adopting amphibious housing options, alongside attending meetings in Baton Rouge, advocating for influence on the state's Coastal Master Plan, and partnering with other tribal communities in coastal regions.

While participants generally agreed that addressing coastal land loss would require community action, attitudes were mixed on how much of a difference could really be made. Many noted that, alongside the cultural aspects of Louisiana that they loved, there was also an attitude of complacency and laissez-faire that would dampen efforts to raise awareness and public pressure. There was general agreement that the public would not be motivated to act until the impacts were immediate and personal, "until it hits your pocketbook"; one participant predicted that it would take "a catastrophic event to the seafood industry before anything's implemented," based on the economic and cultural impacts of the potential loss of Louisiana's fisheries. At the same time, some participants noted the ability of Louisiana's communities to come together during dire conditions, citing the "Cajun Navy" mobilization of private vessels for hurricane search and rescue as an example.

The awareness of the need for political engagement also raised common concerns over corruption and lack of action from the government. Participants expressed that they felt inconsequential and overlooked, with a feeling that "they really don't care about us," referring to government and industry at all levels. A lack of trust in the state government and the city government of New Orleans was common, linked with the state's history of political corruption and perceptions of misappropriation of funds surrounding prior projects and hurricane reconstruction. Distrust in elected officials was matched by dubious feelings about the effectiveness of voting in new representatives who may be more of the same, despite calls for local candidates who understood the issue personally. The federal government was viewed less negatively, as a source for funding and support on the necessary scale, but participants felt that, though federal aid is needed because of misappropriation at the state level, the federal government was doing little to help currently. 
There was little familiarity with state efforts to combat coastal land loss, particularly the Coastal Master Plan, a 50 year state plan to protect and restore Louisiana's coast [1]. Some participants felt that while many studies had been done, little action had come from them despite the money spent. Proposed sediment diversions, large-scale coastal restoration projects engineered to restore natural deltaic processes to build and maintain land, were rarely mentioned but did evoke strong responses from some participants. One participant from Jean Lafitte who was a commercial fisherman said, "I truly despise the diversion," noting that he felt blindsided and feared losing his livelihood. The Plaquemines Parish group discussed the potential for mitigation efforts like sediment diversions to introduce new, unknown risks from human intervention and lack of oversight: "There's supposed to be some type of oversight, but that falls by the wayside oftentimes, and they're mismanaged".

The possibility of relocation as an adaptive response to risk was raised by some participants, including some who had already moved apartments or homes for higher ground: "I'm not going to sit around and wait for something to happen". Relocation was a matter of concern for others, particularly those in locations further inland, the North Shore and Alexandria. Participants in the North Shore group described a wave of postKatrina migration from New Orleans to the North Shore and discussed changing patterns of property ownership and impacts on local tax bases. In Alexandria, participants raised worries about the future impacts of displacement on the housing market, rental prices, and cost of living as coastal residents moved northward. Attitudes about potentially leaving the state were mixed, however, with a reluctance to lose the livelihoods and traditions associated with coastal Louisiana that they would not be able to carry on elsewhere. Feelings about relocation and mitigation responses were also related to attachment to place and to concerns about traumatic impacts on future generations:

People have been talking about relocation, you know, moving populations away from these deemed 'at risk' places. But I think you're trading one set of circumstances for another set of circumstances. And I think there will be a few generations where the people will not fare well, you know, because they're not accounting for that recovery period.

Participants were also asked whether they associated climate change mitigation efforts with benefits for mitigating coastal land loss. Responses were mixed, with some participants seeing the issues as entirely separate, and others feeling that reducing emissions to address climate change did carry over into helping reduce land loss impacts. Though viewing climate change and land loss mitigation as not directly linked, some participants cited the contribution of the oil and gas industry to erosion in coastal Louisiana through the construction of canal networks, and felt that the industry should be required to pay back into mitigation efforts. Others linked climate change mitigation directly with efforts to curb coastal land loss, by reducing storm intensity and a subsequent "domino effect," as one participant put it, of increased erosion and sediment load leading to impacts on water quality and fisheries. Participants' efficacy in reducing their personal emissions was raised as a barrier-however, "you have to have a good income to try and minimize your footprint".

\section{Discussion}

In delving into the contextual dimensions of how residents in this region perceive the pervasive threats of land loss and flooding, our findings provide insight into the challenges of addressing coastal land loss in southern Louisiana. We find that participants are strongly attached to the unique culture and community of Louisiana, and that these attachments act in concert with personal ties to land loss to provide a lens for understanding the immediate impacts of coastal land loss. Risk perception among participants revolved around a sense of exposure, inevitability, and lack of control, which extended beyond the potential for personal harm to the far-reaching ripple effects on Louisiana's economy, culture, and future generations. Personal experiences and social connections, particularly through family, fishing, and food, served as an avenue for risk information and awareness. For many, the 
importance of the seafood industry and the high visibility of negative fisheries impacts provided a reference point for understanding the impacts of land loss. At the time of this study, local oysters were in short supply due to the impacts of severe flooding along the Mississippi River in early 2019 that inundated coastal marshes with freshwater [73]; several participants across the groups highlighted the connection. The prominence of direct and indirect experience as a driver of awareness of coastal land loss impacts agrees with previous research on the role of personal experience, long noted as a strong factor in risk perception [16,74-76]. Our findings add additional nuance to this relationship by noting the importance of direct experience with place and the surrounding landscape as an avenue for direct experience of risk. Experiences with place and hence local risks may also reshape the interpretive schema residents use to understand and interpret climate change information more generally; prior research has indicated that residents rely on interpretive strategies related to personal experience and place to make sense of climate change communications [31].

The close link between risk perception of coastal land loss and the region's distinct ecological and cultural characteristics also highlights the threats posed to place-based identity by coastal land loss. Mentions of food as a favorite aspect of Louisiana life were ubiquitous, emphasizing the seafood industry and its importance for local cuisine and culture. In the discussions, crawfish boils and other food-based gatherings were mentioned as avenues for experiencing and discussing changes to land; Gutierrez [77] notes that the crawfish is a symbol of ethnic and regional identity for those in Cajun Louisiana. Gutierrez describes how crawfish boils function as a cultural ritual that strengthens community ties, which, in concert with our findings, suggests that food and related activities are both pathways to risk awareness and opportunities for enhancing resilience. As noted by Goodall [78], "eating is one of the ways that humans remain directly in contact with their environment, wherever they are" (p. 32), and activities such as fishing and foraging can lead to a heightened sensitivity to environmental changes.

With damages to coastal ecosystems predicted to increase, these connections with place face significant disruption, potentially leading to loss of identity and damage to well-being-as participants noted-but also potentially motivating place-protective action. Indeed, participants focused on the potential for impacts on seafood prices and availability to motivate action, though there was skepticism over how timely such a response would be. While strong attachment to Louisiana's unique qualities may motivate protective actions, it also appears to weaken intentions to take more drastic coping actions like relocation, consistent with prior research on the relationship between place attachment and risk coping behaviors [36]. These findings are also consistent with research on retreatorientated adaptation strategies, which has noted the high social costs and potential for strong opposition based on attachment, history, and cultural heritage [6,79-81].

Capturing the nuances of how place attachment, meanings, and identity relate to the complex reality of coastal land loss also provides further insight into the role of what other research has termed place-based elements in shaping community resilience for climate adaptation $[13,82]$. Understanding the dynamic role of place in shaping climaterelated attitudes and actions requires conceptualizing place-related factors as both potential resource and barrier, and remains an area for further study that takes into account the richness of place relationships. For example, examining weather as a component of sense of place, Butts and Adams [83] suggest that the volatility of local weather in locations like the Outer Hebrides can be a positive dimension of place identity compared to the uncertainty and lack of control over adaptation processes. This is similar to the attitudes expressed by the Grand Bayou Village group in this study, who viewed landscape change as a core characteristic of their coastal sense of place.

Personal risk reduction actions were constrained by limited awareness of actions at the individual or household scale that would reduce one's exposure to risk, but also by a sense of limited efficacy - both self-efficacy, participants' ability to implement a behavior, and response efficacy, whether the behavior would be effective at addressing the risk [22]. 
As a consequence of the perception of the risks as "bigger than us," participants across all six discussions turned the question of mitigation actions away from personal behaviors towards community and government-level action as the only effective means of addressing an issue as large as coastal land loss. A lack of trust in the stakeholders involved in state and federal efforts contributed to a sense of fatalism about addressing land loss, though a sense of strong community, ties to place, and concerns about maintaining place and community for future generations fueled more optimistic outlooks on the effects of collective efforts.

This study is not without limitations; we report findings based only a small sample of Louisiana residents, limiting our ability to generalize results beyond the study context. The qualitative nature of focus groups, however, allows us to capture in-depth explorations of participants' subjective meanings and interpretations that provide theoretical insights for future work. An additional consideration is that our primary means of recruitment was through Facebook advertisements, limiting our sample to social media users sufficiently motivated to attend a meeting on the topic of coastal land loss. Our recruitment efforts faced the inherent challenges of working with a hard-to-reach population, particularly for the Jean Lafitte $(n=6)$ and Plaquemines Parish $(n=4)$ sessions, located in areas of lower population density. Difficulty recruiting participants in the areas most directly affected is a direct reflection of the intricate wetlands landscape central to the question of coastal land loss, with participants at the Plaquemines Parish session needing to travel an hour by boat and by car to reach the session. In addition, the participants at the Plaquemines Parish session were all residents of Grand Bayou Village, and while their experiences represent life in a site of accelerated land loss impacts, they may not be reflective of the rest of the parish. "Research fatigue" with the repeated experience of turning one's personal experiences into an object of study for outsiders [84] may also be a factor in demotivating participation in areas that have been the focus of waves of post-disaster research following such events as Hurricane Katrina and the Deepwater Horizon oil spill [85].

\section{Conclusions}

These findings shed light on role of place attachment, local culture and community, and personal experience in shaping coastal land loss perceptions and mitigation intentions. Personal ties to land loss through family, social connections, experiences with fishing and water-based activities, and indirect impacts on Louisiana's seafood industry and cuisine fueled awareness of impacts of coastal land loss among study participants. The risks of coastal land loss were perceived as "bigger than us" - inevitable and overwhelming at the individual level, and reaching far into the future to affect the next generations and their ability to maintain Louisiana culture. Participants expressed limited knowledge of state and federal mitigation efforts and of individual-level actions that they could take to mitigate their personal exposure to risk. Though expressing a lack of efficacy when discussing personal mitigation actions, they also expressed attitudes of resilience and optimism and focused on mitigation as a matter of political actions and community engagement, tempered by low levels of trust in local and state governments.

What emerges from this picture is the complicated role of place and community attachment in exposure, awareness, and action. While participants with personal ties to risk report feelings of exposure and inevitability, they are also embedded in communities with strong ties to place that complicate the meanings that individuals associate with land loss and the actions that they are motivated to take. The loss of southern Louisiana's distinctive wetlands and the subsequent damage to ecosystems, livelihoods, and traditional culture may lead to significant disruption to place identity and well-being for those who are highly attached, but these attachments also provide a pathway for risk awareness and potential motivation of collective action. Though potentially fueling place-protective actions, these bonds that tie people to place act against other mitigation actions that themselves involve potential disruptions to place and identity, including moving and changing careers.

These findings offer several practical implications for policymakers aiming to develop effective mitigation efforts how people may perceive and respond to them. Firstly, it may 
be beneficial to conceptualize the risks of coastal land loss in terms of the impacts on important cultural symbols and traditions, particularly related to Louisiana's renowned cuisine. This may help to bolster public perception of the threat from coastal land loss and climate change more generally, and bolster perception of the benefits of state and federal mitigation efforts as well as motivate action at the community level. Secondly, though disruptive behaviors such as relocation may be increasingly necessary, they will be especially difficult to motivate among highly attached residents. In contrast, less disruptive behaviors such as supporting policies and taxes to fund mitigation efforts may provide a more conducive avenue for action. In addition, messaging that targets a perceived lack of efficacy with individual and community-level efficacy information may help to attenuate the sense of "it's bigger than us" that overwhelmed many participants, refocusing instead on the opposite sentiment: "Nothing is bigger than us".

Author Contributions: C.E.L.: investigation, formal analysis, and writing-original draft preparation. J.R.H.: methodology, investigation, and formal analysis. K.A.M.: conceptualization, methodology, writing-review and editing, and supervision. N.P.S.: conceptualization, resources, and writing-review and editing. G.K.T.: investigation, resources, and writing-review and editing. All authors have read and agreed to the published version of the manuscript.

Funding: This work was facilitated by Environmental Defense Fund and the Restore the Mississippi River Delta Coalition and funded and made possible by the Walton Family Foundation.

Institutional Review Board Statement: This study was approved by the Institutional Review Board of Cornell University.

Informed Consent Statement: Informed consent was obtained from all participants involved in this study.

Data Availability Statement: Due to the nature of this research, participants of this study did not agree for their data to be shared publicly, so session transcripts are not available.

Acknowledgments: We are sincerely grateful for the participants who generously shared their time and experiences with us. We would also like to thank the following people for their assistance in outreach and recruitment: Jacques Hebert, Helen Rose Patterson, Corey Miller, Amanda Moore, Samantha Carter, Charles Allen, Erin Willhoft, Steve Cochran, Katie Denman, Simone Maloz, Faye Matthews, Taylor Laurent, and Joel Campbell.

Conflicts of Interest: The authors declare no conflict of interest.

\section{References}

1. Coastal Protection and Restoration Authority, Louisiana's Comprehensive Master Plan for a Sustainable Coast. 2017. Available online: http:/ / coastal.la.gov/our-plan/2017-coastal-master-plan/ (accessed on 3 August 2020).

2. Couvillion, B.R.; Beck, H.; Schoolmaster, D.; Fischer, M. Land Area Change in Coastal Louisiana (1932 to 2016). In U.S. Geological Survey Scientific Investigations Map 3381; U.S. Geological Survey: Reston, VA, USA, 2017. [CrossRef]

3. Törnqvist, T.E.; Jankowski, K.L.; Jankowski, K.L.; Li, Y.X.; González, J.L. Tipping points of Mississippi Delta marshes due to accelerated sea-level rise. Sci. Adv. 2020, 6. [CrossRef]

4. Gaudet, M. Mardi Gras, Gumbo, and Zydeco: An Introduction to Louisiana Culture. In Mardi Gras, Gumbo, and Zydeco: Readings in Louisiana Culture; Gaudet, M., McDonald, J.C., Eds.; University Press of Mississippi: Jackson, MS, USA, 2003; Available online: http:/ / ebookcentral.proquest.com/lib/cornell/detail.action?docID=746920 (accessed on 1 September 2020).

5. Sinay, L.; Carter, R.W.B. Climate Change Adaptation Options for Coastal Communities and Local Governments. Climate 2020,8 , 7. [CrossRef]

6. Dedekorkut-Howes, A.; Torabi, E.; Howes, M. When the tide gets high: A review of adaptive responses to sea level rise and coastal flooding. J. Environ. Plan. Manag. 2020, 63, 2102-2143. [CrossRef]

7. Biesbroek, G.R.; Klostermann, J.E.M.; Termeer, C.J.A.M.; Kabat, P. On the nature of barriers to climate change adaptation. Reg. Environ. Chang. 2013, 13, 1119-1129. [CrossRef]

8. McNamara, K.E.; Buggy, L. Community-based climate change adaptation: A review of academic literature. Local Environ. 2017, 22, 443-460. [CrossRef]

9. Hurlimann, A.; Barnett, J.; Fincher, R.; Osbaldiston, N.; Mortreux, C.; Graham, S. Urban planning and sustainable adaptation to sea-level rise. Landsc. Urban Plan. 2014, 126, 84-93. [CrossRef]

10. Hügel, S.; Davies, A.R. Public participation, engagement, and climate change adaptation: A review of the research literature, Wiley Interdiscip. Rev. Clim. Chang. 2020, 11, 1-20. [CrossRef] 
11. Jurjonas, M.; Seekamp, E. Rural coastal community resilience: Assessing a framework in eastern North Carolina. Ocean Coast. Manag. 2018, 162, 137-150. [CrossRef]

12. Casey, A.; Becker, A. Institutional and Conceptual Barriers to Climate Change Adaptation for Coastal Cultural Heritage. Coast. Manag. 2019, 47, 169-188. [CrossRef]

13. Galappaththi, E.K.; Ford, J.D.; Bennett, E.M. A framework for assessing community adaptation to climate change in a fisheries context. Environ. Sci. Policy 2019, 92, 17-26. [CrossRef]

14. Plough, A.; Krimsky, S. The Emergence of Risk Communication Studies: Social and Political Context. Sci. Technol. Hum. Values 1987, 12, 4-10.

15. Slovic, P. Perception of Risk. Science 1987, 236, 280-285. [CrossRef]

16. Wachinger, G.; Renn, O.; Begg, C.; Kuhlicke, C. The risk perception paradox-implications for governance and communication of natural hazards. Risk Anal. 2013, 33, 1049-1065. [CrossRef]

17. Haney, T.J. Move out or dig in? Risk awareness and mobility plans in disaster-Affected communities. J. Conting. Cris. Manag. 2018, 1-13. [CrossRef]

18. Gotham, K.F.; Campanella, R.; Lauve-Moon, K.; Powers, B. Hazard Experience, Geophysical Vulnerability, and Flood Risk Perceptions in a Postdisaster City, the Case of New Orleans. Risk Anal. 2018, 38, 345-356. [CrossRef]

19. Bergquist, M.; Nilsson, A.; Schultz, P.W. Experiencing a severe weather event increases concern about climate change. Front. Psychol. 2019, 10, 1-6. [CrossRef]

20. Zanocco, C.; Boudet, H.; Nilson, R.; Flora, J. Personal harm and support for climate change mitigation policies: Evidence from 10 U.S. communities impacted by extreme weather. Glob. Environ. Chang. 2019, 59, 101984. [CrossRef]

21. Lang, C.; Ryder, J.D. The effect of tropical cyclones on climate change engagement. Clim. Chang. 2016, 135, 625-638. [CrossRef]

22. Bubeck, P.; Botzen, W.J.W.; Aerts, J.C.J.H. A Review of Risk Perceptions and Other Factors that Influence Flood Mitigation Behavior. Risk Anal. 2012, 32, 1481-1495. [CrossRef] [PubMed]

23. Rogers, R.W. A Protection Motivation Theory of Fear Appeals and Attitude Change. J. Psychol. 1975, 91, 93-114. [CrossRef] [PubMed]

24. Bubeck, P.; Botzen, W.J.W.; Kreibich, H.; Aerts, J.C.J.H. Detailed insights into the influence of flood-coping appraisals on mitigation behaviour. Glob. Environ. Chang. 2013, 23, 1327-1338. [CrossRef]

25. Grothmann, T.; Reusswig, F. People at risk of flooding: Why some residents take precautionary action while others do not. Nat. Hazards. 2006, 38, 101-120. [CrossRef]

26. Lindell, M.K.; Perry, R.W. The Protective Action Decision Model: Theoretical Modifications and Additional Evidence. Risk Anal 2012, 32, 616-632. [CrossRef] [PubMed]

27. Osberghaus, D. The effect of flood experience on household mitigation-Evidence from longitudinal and insurance data. Glob. Environ. Chang. 2017, 43, 126-136. [CrossRef]

28. Thistlethwaite, J.; Henstra, D.; Brown, C.; Scott, D. How Flood Experience and Risk Perception Influences Protective Actions and Behaviours among Canadian Homeowners. Environ. Manag. 2018, 61, 197-208. [CrossRef]

29. Morss, R.E.; Cuite, C.L.; Demuth, J.L.; Hallman, W.K.; Shwom, R.L. Is storm surge scary? The influence of hazard, impact, and fear-based messages and individual differences on responses to hurricane risks in the U.S. Int. J. Disaster Risk Reduct. 2018, 30, 44-58. [CrossRef]

30. Nkoana, E.M.; Verbruggen, A.; Hugé, J. Climate change adaptation tools at the community level: An integrated literature review. Sustainability 2018, 10, 796. [CrossRef]

31. Ballantyne, A.G.; Glaas, E.; Neset, T.; Wibeck, V. Localizing climate change: Nordic homeowners' interpretations of visual representations for climate adaptation. Environ. Commun. 2018, 12, 638-652. [CrossRef]

32. Low, S.M.; Altman, I. Place Attachment: A Conceptual Inquiry. In Place Attachment; Altman, I., Low, S.M., Eds.; Springer: Boston, MA, USA, 1992; pp. 1-12.

33. Stedman, R.C. Toward a Social Psychology of Place: Predicting Behavior From Place-Based Cognitions, Attitude, and Identity. Environ. Behav. 2002, 34, 561-581. [CrossRef]

34. Marcus, C.C. Environmental Memories. In Place Attachment; Altman, I., Low, S.M., Eds.; Springer: Boston, MA, USA, 1992; pp. 87-112.

35. Brown, B.B.; Perkins, D.D. Disruption in place attachment. In Place Attachment; Altman, I., Low, S.M., Eds.; Springer: Boston, MA, USA, 1992; pp. 279-304.

36. Bonaiuto, M.; Alves, S.; de Dominicis, S.; Petruccelli, I. Place attachment and natural hazard risk: Research review and agenda. J. Environ. Psychol. 2016, 48, 33-53. [CrossRef]

37. Bonaiuto, M.; Breakwell, G.M.; Cano, I. Identity Processes and Environmental Threat: The Effects of Nationalism and Local Identity upon Perception of Beach Pollution. J. Community Appl. Soc. Psychol. 1996, 6, 157-175. [CrossRef]

38. Marcu, A.; Uzzell, D.; Barnett, J. Making sense of unfamiliar risks in the countryside: The case of Lyme disease. Health Place 2011, 17, 843-850. [CrossRef]

39. Armaş, I. Earthquake Risk Perception in Bucharest, Romania. Risk Anal. 2006, 26, 1223-1234. [CrossRef]

40. Donovan, K.; Suryanto, A.; Utami, P. Mapping cultural vulnerability in volcanic regions: The practical application of social volcanology at Mt Merapi, Indonesia. Environ. Hazards 2012, 11, 303-323. [CrossRef] 
41. Billig, M. Is My Home My Castle? Place Attachment, Risk Perception, and Religious Faith. Environ. Behav. 2006, 38, $248-265$. [CrossRef]

42. Dallago, L.; Perkins, D.D.; Santinello, M.; Will, A.; Ae, B.; Molcho, M.; Morgan, A. Adolescent Place Attachment, Social Capital, and Perceived Safety: A Comparison of 13 Countries. Am. J. Community Psychol. 2009, 44, 148-160. [CrossRef] [PubMed]

43. Wareham-Fowler, S.; Fowler, K. Risk perception, safety behaviour, employment precarity and community attachment: The case of Newfoundland and Labrador fibreglass boat-building workers. Policy Pract. Health Saf. 2010, 8, 43-60. Available online: https: / / search.proquest.com/docview /1144951971?pq-origsite=gscholar (accessed on 20 November 2017). [CrossRef]

44. de Dominicis, S.; Fornara, F.; Cancellieri, U.G.; Twigger-Ross, C.; Bonaiuto, M. We are at risk, and so what? Place attachment, environmental risk perceptions and preventive coping behaviours. J. Environ. Psychol. 2015, 43, 66-78. [CrossRef]

45. Willox, A.C.; Harper, S.L.; Ford, J.D.; Landman, K.; Houle, K.; Edge, V.L. "From this place and of this place" Climate change, sense of place, and health in Nunatsiavut, Canada. Soc. Sci. Med. 2012, 75, 538-547. [CrossRef]

46. Boon, H.J. Disaster resilience in a flood-impacted rural Australian town. Nat. Hazards 2014, 71, 683-701. [CrossRef]

47. Bird, D.K.; Gísladóttir, G.; Dominey-Howes, D. Different communities, different perspectives: Issues affecting residents' response to a volcanic eruption in southern Iceland. Bull. Volcanol. 2011, 73, 1209-1227. Available online: https://rafhladan.is/bitstream/ handle/10802/12580/Different\%communities.pdf?sequence=1 (accessed on 1 April 2021). [CrossRef]

48. Kick, E.L.; Fraser, J.C.; Fulkerson, G.M.; McKinney, L.A.; de Vries, D.H. Repetitive flood victims and acceptance of FEMA mitigation offers: An analysis with community-system policy implications. Disasters 2011, 35, 510-539. [CrossRef] [PubMed]

49. Lavigne, F.; de Coster, B.; Juvin, N.; Flohic, F.; Texier, P.; Morin, J.; Sartohadi, J. People's behaviour in the face of volcanic hazards: Perspectives from Javanese communities, Indonesia. J. Volcanol. Geotherm. Res. 2008, 172, 273-287. [CrossRef]

50. Paton, D.; Bürgelt, P.T.; Prior, T. Living with bushfire risk: Social and environmental influences on preparedness. Aust. J. Emerg. Manag. 2008, 23, 41-48.

51. Pirta, R.S.; Chandel, N.; Pirta, C. Loss of home at early age: Retrieval of memories among the displacees of Bhakra Dam after fifty years. J. Indian Acad. Appl. Psychol. 2014, 40, 78-85.

52. Zhang, Y.; Zhang, H.-L.; Zhang, J.; Cheng, S. Predicting residents' pro-environmental behaviors at tourist sites: The role of awareness of disaster's consequences, values, and place attachment. J. Environ. Psychol. 2014, 40, 131-146. [CrossRef]

53. Stain, H.J.; Kelly, B.; Carr, V.J.; Lewin, T.J.; Fitzgerald, M.; Fragar, L. The psychological impact of chronic environmental adversity: Responding to prolonged drought. Soc. Sci. Med. 2011, 73, 1593-1599. [CrossRef]

54. Gallina, M.; Williams, A. Perceptions of Air Quality and Sense of Place among Women in Northeast Hamilton, Ontario, Canada. Int. J. Soc. Sci. Stud. 2014, 2, 67-77. [CrossRef]

55. Kaltenborn, B.P. Effects of sense of place on responses to environmental impacts: A study among residents in Svalbard in the Norwegian high Arctic. Appl. Geogr. 1998, 18, 169-189. [CrossRef]

56. Collins, T.W. What Influences Hazard Mitigation? Household Decision Making About Wildfire Risks in Arizona's White Mountains. Prof. Geogr. 2008, 60, 508-526. [CrossRef]

57. Silver, A.; Grek-Martin, J. "Now we understand what community really means": Reconceptualizing the role of sense of place in the disaster recovery process. J. Environ. Psychol. 2015, 42, 32-41. [CrossRef]

58. Mishra, S.; Mazumdar, S.; Suar, D. Place attachment and flood preparedness. J. Environ. Psychol. 2010, 30, 187-197. [CrossRef]

59. Quinn, T.; Bousquet, F.; Guerbois, C.; Heider, L.; Brown, K. How local water and waterbody meanings shape flood risk perception and risk management preferences. Sustain. Sci. 2019, 1, 3. [CrossRef]

60. ASikder, H.M.K.; Mozumder, P. Risk Perceptions and Adaptation to Climate Change and Sea-Level Rise: Insights from General Public Opinion Survey in Florida. J. Water Resour. Plan. Manag. 2020, 146. [CrossRef]

61. Urquhart, J.; Acott, T. A Sense of Place in Cultural Ecosystem Services: The Case of Cornish Fishing Communities. Soc. Nat. Resour. 2014, 27, 3-19. [CrossRef]

62. Acott, T.G.; Urquhart, J. Sense of Place and Socio-Cultural Values in Fishing Communities Along the English Channel. In Social Issues in Sustainable Fisheries Management; Urquhart, J., Acott, T.G., Symes, D., Zhao, M., Eds.; Springer: Dordrecht, The Netherlands, 2014; pp. 257-277. [CrossRef]

63. Khakzad, S.; Griffith, D. The role of fishing material culture in communities' sense of place as an added-value in management of coastal areas. J. Mar. Isl. Cult. 2016, 5, 95-117. [CrossRef]

64. Donkersloot, R.; Menzies, C. Place-based fishing livelihoods and the global ocean: The Irish pelagic fleet at home and abroad. Marit. Stud. 2015, 14, 1-19. [CrossRef]

65. O'Sullivan, A. Place, memory and identity among estuarine fishing communities: Interpreting the archeology of early medieval fish weirs. World Archaeol. 2004, 35, 449-468. [CrossRef]

66. National Marine Fisheries Service, Fisheries of the United States, 2018. 2020. Available online: https://www.fisheries.noaa.gov/ national/commercial-fishing/fisheries-united-states-2018 (accessed on 15 April 2021).

67. Burley, D.; Jenkins, P.; Laska, S.; Davis, T. Place Attachment and Environmental Change in Coastal Louisiana. Organ. Environ. 2007, 20, 347-366. [CrossRef]

68. Chamlee-Wright, E.; Storr, V.H. “There's No Place like New Orleans": Sense of Place and Community Recovery in the Ninth Ward after Hurricane Katrina. J. Urban Aff. 2009, 31, 615-634. [CrossRef]

69. Bessette, D.L.; Mayer, L.A.; Cwik, B.; Vezér, M.; Keller, K.; Lempert, R.J.; Tuana, N. Building a Values-Informed Mental Model for New Orleans Climate Risk Management. Risk Anal. 2017, 37, 1993-2004. [CrossRef] [PubMed] 
70. Atlas.ti. 2020. Available online: Atlasti.com (accessed on 1 April 2021).

71. Charmaz, K. Qualitative interviewing and grounded theory analysis. In Handbook of Interview Research: Context E Method; Gubrium, J.F., Holstein, J.A., Eds.; Sage Publications: Thousand Oaks, CA, USA, 2002; pp. 675-694.

72. Coastwide Nutria Control Program. 2020. Available online: https://www.lacoast.gov/reports/gpfs/LA-03b.pdf (accessed on 13 November 2020).

73. Anderson, B. Gulf Oysters Are Dying, Putting a Southern Tradition at Risk—The New York Times. New York Times, 12 November 2019. Available online: https://www.nytimes.com/2019/11/12/dining/gulf-oysters.html(accessed on 31 August 2020).

74. Ruin, I.; Gaillard, J.; Lutoff, C. How to get there? Assessing motorists' flash flood risk perception on daily itineraries. Environ. Hazards 2007, 7, 235-244. [CrossRef]

75. Siegrist, M.; Gutscher, H. Flooding risks: A comparison of lay people's perceptions and expert's assessments in Switzerland. Risk Anal. 2006, 26, 971-979. [CrossRef] [PubMed]

76. Miceli, R.; Sotgiu, I.; Settanni, M. Disaster preparedness and perception of flood risk: A study in an alpine valley in Italy. J. Environ. Psychol. 2008, 28, 164-173. [CrossRef]

77. Gutierrez, C.P. The Social and Symbolic Uses of Ethnic/Regional Foodways: Cajuns and Crawfish in South Louisiana. In Mardi Gras, Gumbo, Zydeco: Readings in Louisiana Culture; Gaudet, M., McDonald, J.C., Eds.; University Press of Mississippi: Jackson, MS, USA, 2003.

78. Goodall, H. Rivers, Memory and Migrancy: Everyday Place-Making in Changing Environments. In Telling Environmental Histories; Holmes, K., Goodall, H., Eds.; Palgrave: London, UK, 2017; pp. 31-49. [CrossRef]

79. Primo, L.H. Sea-level rise vulnerability of Kosrae, Federated States of Micronesia and strategies for adaption. J. Coast. Res. 1997, 24, 107-115.

80. Lonsdale, K.G.; Downing, T.E.; Nicholls, R.J.; Parker, D.; Vafeidis, A.T.; Dawson, R.; Hall, J. Plausible responses to the threat of rapid sea-level rise in the Thames Estuary. Clim. Chang. 2008, 91, 145-169. [CrossRef]

81. Alexander, K.S.; Ryan, A.; Measham, T.G. Managed retreat of coastal communities: Understanding responses to projected sea level rise. J. Environ. Plan. Manag. 2012, 55, 409-433. [CrossRef]

82. Galappaththi, E.K.; Ford, J.D.; Bennett, E.M. Climate change and adaptation to social-ecological change: The case of indigenous people and culture-based fisheries in Sri Lanka. Clim. Chang. 2020, 162, 279-300. [CrossRef]

83. Butts, D.; Adams, H. Weather Contracts: Capturing a sense of weather for place-based adaptation to climate change. Glob. Environ. Chang. 2020, 63, 102052. [CrossRef]

84. Clark, T. "We're over-researched here!": Exploring accounts of research fatigue within qualitative research engagements. Sociology 2008, 42, 953-970. [CrossRef]

85. Lesen, A.E.; Tucker, C.; Olson, M.G.; Ferreira, R.J. “Come back at us": Reflections on researcher-community partnerships during a post-oil spill gulf coast resilience study. Soc. Sci. 2019, 8, 8. [CrossRef] 